\title{
Vinylogous urea vitrimers and their application in fiber reinforced composites
}

\author{
Wim Denissen ${ }^{1}$, Ives De Baere ${ }^{2}$, Wim Van Paepegem², Ludwik Leibler, Johan Winne*1, Filip E. Du \\ Prez*1 \\ ${ }^{1}$ Department of Organic and Macromolecular Chemistry, Polymer Chemistry Research Group and Laboratory for Or- \\ ganic Synthesis, Ghent University, Krijgslaan 281 S4-bis, B-9000 Ghent, Belgium. \\ ${ }^{2}$ Department of Materials Science \& Engineering, Ghent University, Technologiepark-Zwijnaarde 903, B-9052 \\ Zwijnaarde, Belgium \\ ${ }^{3}$ ESPCI Paris, PSL Research University, 10 rue Vauquelin, 75005 Paris, France
}

Keywords: vitrimers, dynamic chemistry, covalent adaptable networks, vinylogous acyls

\begin{abstract}
Vitrimers are covalently cross-linked polymeric materials that can be thermally processed in a liquid state without losing their network integrity. In this work, novel vitrimers based on the dynamic amine exchange reaction of vinylogous urea moieties are introduced. Following a systematic exploration of different vinylogous acyl compounds (urethanes, amides and urea), vinylogous urea clearly emerge as showing the fastest intrinsic exchange kinetics. The combination of these networks with a simple acid catalyst $(0.5 \mathrm{~mol} \% \mathrm{pTsOH})$ resulted in materials with good mechanical properties $\left(\mathrm{Tg} \sim 110^{\circ} \mathrm{C}, \mathrm{E} \sim 2.2 \mathrm{GPa}\right.$ ) and remarkably short relaxation times above $\mathrm{Tg}$, in the order of a few seconds when heated. This attractive combination of properties made it possible to prepare vinylogous urea based composites as enduring prepregs. We demonstrate that the dynamic material properties give fully cured composites that still allow an efficient thermal fusion of multiple layers as well as thermoforming. Finally, we also demonstrate fiber-recycling by a simple chemical treatment.
\end{abstract}

\section{Introduction}

In 2011, vitrimers were reported by Leibler and coworkers as a new class of organic materials and their unique features immediately suggested great promise for industrial applications that rely on the assets of a crosslinked polymer structure ${ }^{1-3}$. In essence, vitrimers combine the mechanical properties and insolubility of cross-linked materials with a gradual viscosity decrease when heated, reminiscent to silica glasses (i.e. strong glass-formers). ${ }^{1-4}$ These properties are achieved by incorporation of thermally triggered exchangeable bonds that follow an associative exchange process. Because of this particular exchange mechanism, vitrimers are characterised by a constant cross-link density. These numbers do not fluctuate in time and do not vary when the temperature is changed. This feature differentiates vitrimers from thermoreversible networks that are characterized by a fluctuating cross-link density and can even go below the percolation threshold, resulting in a sharp viscosity drop. ${ }^{5-7}$ The pioneering vitrimers relied on catalyzed transesterification and in the meantime, quite a few other exchange chemistries were found for organic networks, such as aromatic disulfide metathesis, ${ }^{8}$ transalkylation of triazolium salts, ${ }^{9}$ olefin metathesis, ${ }^{10-11}$ amine exchange of vinylogous urethanes ${ }^{12-}$ 13, imine metathesis ${ }^{14-16}$, transesterification of boronic esters $^{17}$ and very recently transalkylation of trialkylsulfonium salts ${ }^{18}$ and diboroxolane metathesis ${ }^{19}$. An overview of most of these chemistries and can be found in recent reviews on vitrimers ${ }^{20}$ and dynamic networks in general $^{21-22}$.

While all the different associative bond exchange chemistries show interesting features with specific assets useful for certain applications, one of the most important vitrimer properties is the interplay between mechanical properties and the intrinsic exchange kinetics since these directly influence the processability and the dimensional stability of a vitrimer network. For example, for an elastomer vitrimer, the kinetics need to be very well balanced in a manner that no creep occurs at room temperature or service temperature, while fast exchange should still be accessible at typical processing ${ }^{13}$. In contrast, for hard materials with glass transition temperature $\left(\mathrm{T}_{\mathrm{g}}\right)$ above room temperature reactions with fast exchange kinetics could be of great interest. Indeed, chain motions at large scale are blocked at service temperatures below the glass transition temperature and creep is reduced like in standard thermoplastics. The possibility of easy processing above $\mathrm{T}_{\mathrm{g}}$ is then preserved and thanks to cross-linking the chemical resistance is improved below $\mathrm{T}_{\mathrm{g}}$ at service temperatures ${ }^{19}$. An alternative route of synthesis of hard vitrimers relies on solidification by crystallization ${ }^{23-24}$.

Vitrimer materials that combine a high $\mathrm{T}_{\mathrm{g}}$ and good mechanical properties with the ability to be processed very fast above $\mathrm{T}_{\mathrm{g}}$ could prove to be extremely interesting polymer matrices. In particular fast exchange kinetics could be a boon in the area of composites ${ }^{19}$. So far reinforcement by glass or carbon fibers far has been demonstrated for vitrimers based on transesterification ${ }^{25}$, aromatic disulfide ${ }^{26-27}$ and imine exchange chemistry. ${ }^{15}$, Fiber reinforced polymer composites (FRPC), receive quite some attention from industry, as the search for lightweight alternatives to metals is intensified, driven by the objectives to cut energy consumption and maximize resource efficiency. FRPCs are already widely used in aerospace industry and are expected to be one of the materials of choice in the future of the automotive industry. Adapting the current FRPC- 
production processes to mass production environments remains challenging. From the point of material recycling, current FRPC's show very little prospects while FRPCs based on a vitrimer matrix present opportunities to process, recycle, repair and even separate the fibers from a polymer matrix. Using fast and robust exchange reactions could open interesting perspectives for thermoforming, assembling or repairing FRCPs with cross-linked matrices.

With the aim to arrive at a vitrimer matrix useful for composite production, we wanted to explore the amine exchange in vinylogous acyl based networks. In recent work, we reported the amine exchange of vinylogous urethanes as a promising dynamic chemistry for vitrimers ${ }^{12}$ and more recently also showed that these exchange kinetics can be tuned, remarkably both by acceleration (catalysis) or slowing down (inhibition) through acid and base additives, respectively ${ }^{13}$. In our quest to arrive at very fast exchange reactions in high $\mathrm{Tg}$ materials, we extended in this work the kinetic study to the vinylogous urea and vinylogous amide moieties. Surprisingly, vinylogous urea despite their close chemical similarity - showed much faster intrinsic exchange kinetics than the previously investigated vinylogous urethanes, albeit with a similar activation energy (and thus overall temperature dependence). Herein, we report the development of vinylogous urea vitrimers, their interesting properties and a proof of concept for their use in the preparation of FRPCs.

\section{Results and discussion}

\section{Model studies on enaminone-amine exchange kinetics}

In order to assess the kinetics of the amine exchange of different enaminone functions, low MW model compounds of each considered class were prepared, i.e. vinylogous urea, urethanes, and amides. Despite the marked chemical similarities between these classes of vinylogous acyl-type functions, we were curious to see if minor structural modifications could yield changes in exchange kinetics and activation energies, which could be quite beneficial to the macroscopic properties and the processing conditions of the final material. Moreover, we were interested to see how these alternative chemistries would hold up in a materials context in terms of ease of synthesis and stability. Thus, a range of $N$-butyl- and $N$-benzyl amine enaminone compounds were prepared (Figure 1a). The butyl (1a-4a) and the benzyl (1b-4b) compounds can be readily distinguished using ${ }^{1} \mathrm{H}$ NMR, offering a straightforward way to monitor the rate of the amine exchange reactions (Figure 1b).

In a typical kinetic measurement, the butyl compounds 1-4a were mixed with a fivefold excess of benzyl amine in order to obtain a pseudo-first order reaction in the early stages of the exchange. Furthermore, concentrations were chosen such that they were optimal for ${ }^{1} \mathrm{H}-\mathrm{NMR}$ characterization (approximately $10 \mathrm{mg}$ in $0.65 \mathrm{~mL}$ ). For sake of comparison, the same concentrations were used for the different vinylogous acyl moieties. a)
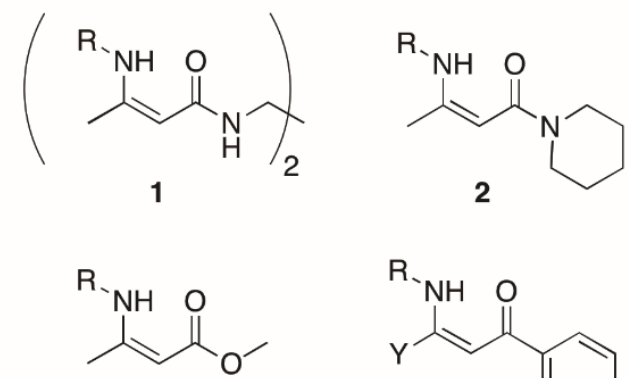

3

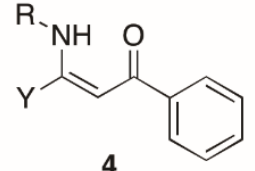

b)

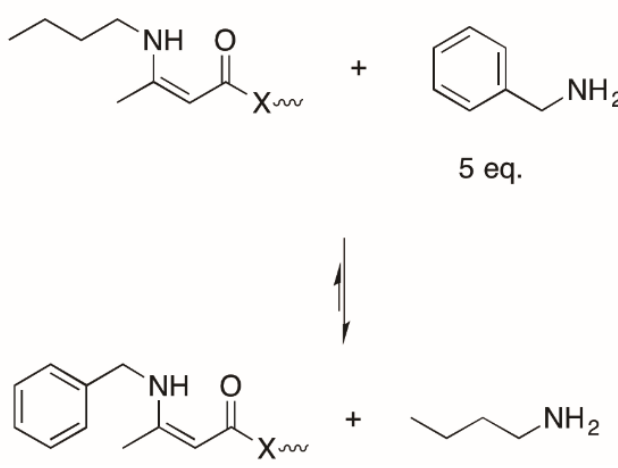

Figure 1. a) Different vinylogous acyl compounds prepared for the model study, $\mathrm{R}=\mathrm{Bn}$ or $\mathrm{Bu}$. b) Generic approach to assess the vinylogous transamination exchange kinetics using low MW model compounds (X $=0$-alkyl, $\mathrm{N}$-(di)alkyl or aryl).

In previous work, we already demonstrated that vinylogous urethanes such as $\mathbf{3}$ undergo swift exchange starting from $100^{\circ} \mathrm{C}$ (Figure S1, Supporting Information) with an activation energy of around $60 \mathrm{~kJ} / \mathrm{mol}^{12}$ The obtained data for 1-4 is summarized in the Arrhenius plots using the $k$-values obtained by fitting the reaction rate curves obtained by ${ }^{1} \mathrm{H}$ NMR (

Figure 2a, for all kinetic data, see Table S1, Supporting Information). For the vinylogous urethane $\mathbf{3}$, which is the reference compound in this study ${ }^{12}$, the expected reaction rate is found with an activation energy of $59 \pm 6 \mathrm{~kJ} \cdot \mathrm{mol}^{-1}$. Interestingly, and quite unexpectedly, both vinylogous ureas 1 and 2 (Figure S2 and S3, Supporting Information) and vinylogous amide (Figure S4, Supporting Information) showed remarkably different exchange kinetics. The vinylogous amide 4 clearly undergoes exchange much slower than the vinylogous urethane reference compound, but also has a significantly lower activation energy (38 \pm 3 kJ.mol ${ }^{-1}$ ). In stark contrast, the vinylogous urea $\mathbf{1}$ and $\mathbf{2}$ already show fast amine exchange at room temperature, with the primary urea slightly faster than secondary urea $\mathbf{2}$ (Figures S3 and S4, Supporting Information). The vinylogous urea $\mathbf{1}$ and $\mathbf{2}$ have a similar activation energy for exchange, respectively $54 \pm 6 \mathrm{~kJ} \cdot \mathrm{mol}^{-1}$ and $49 \pm 1 \mathrm{~kJ} \cdot \mathrm{mol}^{-1}$, thus only slightly lower than that of the reference urethane 3. 


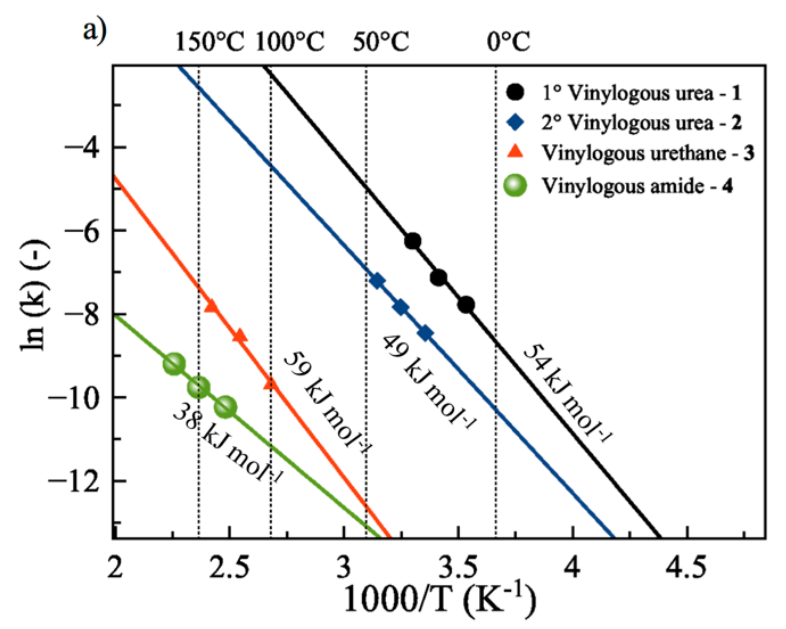

b)

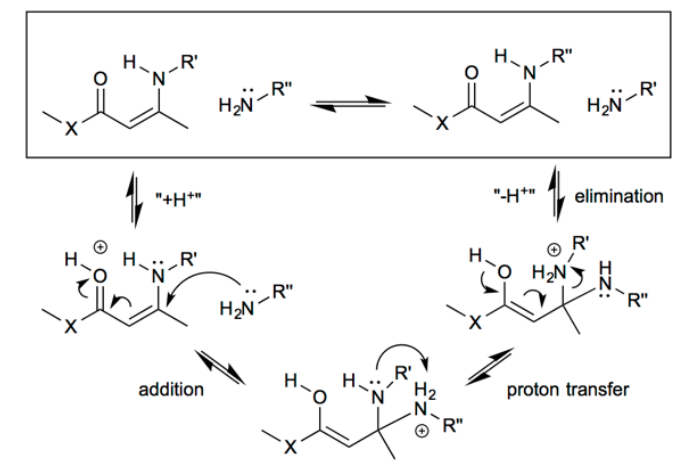

Figure 2. a) Arrhenius plot of the amine exchange of different vinylogous acyl compounds. b) Proposed protonationmediated exchange mechanism.

From these experiments, it can be concluded that the rate of amine exchange on enaminone compounds, as shown in Figure 2a, is in fact strongly dependent on the nature of the X-group bonded to the carbonyl function, in which a trend can be observed where more electron donating X-groups seem to result in markedly faster exchange reactions. This is not an obvious effect, but a possible mechanistic rationale can be found in an exchange mechanism, in which the enamine function needs to be protonated before it can undergo nucleophilic attack by an amine (Figure 2b). This mechanistic picture emerged from our previous observations on vinylogous urethanes where the availability of a good proton source was crucial for fast amine exchange reaction rates. ${ }^{13}$ The reactivity of the enaminone moieties can thus be expected to depend on the electron density of the carbonyl, which is increased as the $\mathrm{X}$-group becomes more electron donating ( $\mathrm{C}>\mathrm{O} \rightarrow \mathrm{N}$ ). In line with this explanation, we indeed find that addition of a proton donor (acid catalyst) further increases the exchange rates strongly for all three classes of vinylogous acyls (Table S1, Figure S5, Supporting Information).

Based on the interesting findings of the kinetic study described above, we were encouraged to further explore vinylogous urea moieties as possible exchangeable links in vitrimer materials, as they offer perspectives for very fast processing. Vinylogous amides were deemed less interesting because of their slow exchange as well as their low activation energy.

\section{Vinylogous urea networks}

Vinylogous urea can be readily assembled from amines and acetoamide monomers through a spontaneous condensation reaction, just as vinylogous urethanes can be assembled from amines and acetoacetates (Figure 3a). Using this straightforward synthesis strategy, three polymer networks were prepared. For the acetoacetamide monomers, ethylenediamine$\mathrm{N}, \mathrm{N}^{\prime}$-bis(acetoacetamide) 5 $4-$ (phenylene)bis(acetoacetamide) 6 and 1,4-(piperazine)bis (acetoacetamide) 7 were selected (Figure 3b). Acetoacetamide $\mathbf{5}$ is commercially available (popular ingredient in paints) while 6 and 7 were easily obtained in one step by acetoacetylation of the corresponding diamine monomers, namely 1,4diaminobenzene and piperazine (see experimental for synthetic procedure). Vinylogous urea networks were prepared by mixing the selected acetoacetamides with a specific ratio of the common tri- and bifunctional amine monomers $\mathbf{8}$ and $\mathbf{9}$, a formulation based on our experiences with our previously developed vinylogous urethane vitrimers ${ }^{12}$. After mixing, a thermal curing step of $3 \mathrm{~h}$ at $150^{\circ} \mathrm{C}$ was performed in a vacuum oven, to ensure complete conversion and removal of the generated water. The materials obtained from the acetoacetamide monomers 5, $\mathbf{6}$ and $\mathbf{7}$ were named Vurea-1, Vurea-2 and Vurea-3, respectively. IR-analysis of the Vurea networks showed a complete disappearance of the $\mathrm{C}=0$ stretch of the ketone around $1700 \mathrm{~cm}^{-1}$, indicating full conversion (Figure S6, Supporting Information).

The obtained Vurea networks were subjected to TGAmeasurements to assess their thermal stability. In contrast to the corresponding Vurethane networks, some of these materials showed significant degradation at temperatures below $200^{\circ} \mathrm{C}$. For more informative measurements, we purposely used a relatively slow heating rate of $1^{\circ} \mathrm{C} \mathrm{min}^{-1}$, as it subjects the samples to a thermal treatment that is similar to that in vitrimer processing (i.e. several minutes at a certain temperature range, rather than seconds). A shift of approximately $25-50^{\circ} \mathrm{C}$ was observed for the onset and progress of mass loss between the TGA-thermograms of Vurea- 1 with a heating rate of $10^{\circ} \mathrm{C} \mathrm{min}-1$ and $1^{\circ} \mathrm{C} \mathrm{min}-1$ (Figure S7, Supporting Information). For clarity, the slow heating TGA curves and their first derivative (DTGA) are shown in Figure 4, which allows to assess the temperature point of initial mass loss for all three Vurea networks. Vurea-1 and Vurea-2 both displayed degradation below $200^{\circ} \mathrm{C}$, which is not acceptable for our intended goal. We believe this is due to a primary urea degradation mechanism (Figure S8, Supporting Information). Significantly, the Vurea-3, based on a secondary vinylogous amide functionality, clearly shows that no significant mass loss occurs before temperatures well above $200^{\circ} \mathrm{C}$, even at this slow heating rate, with the samples surviving more than an hour without mass loss at temperatures above $150^{\circ} \mathrm{C}$. Because of the superior thermal stability of Vurea-3, this composition was chosen for further in-depth characterisation. 
a)

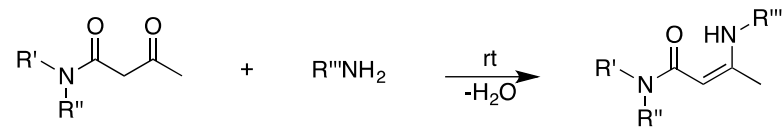

b)

Vurea-1<smiles>CC(=O)CC(=O)NCCNC(=O)CC(C)=O</smiles>

or

Vurea-2

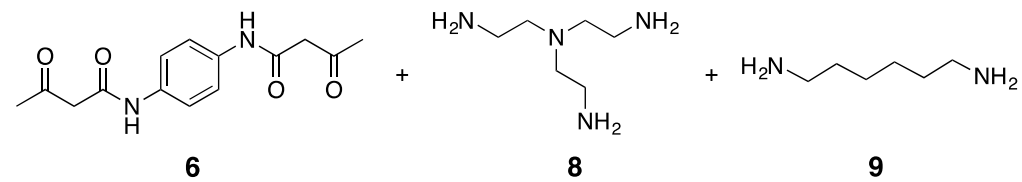

Vurea-3

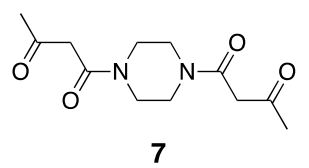

Figure 3. a) Vinylogous urea formation by condensation of an amine with acetoamide monomers through a spontaneous condensation reaction. b) Three different Vurea networks prepared by mixing acetoacetamide (5,6 or 7):triamine 8:diamine 9 in a ratio of 0.95:0.40:0.40.

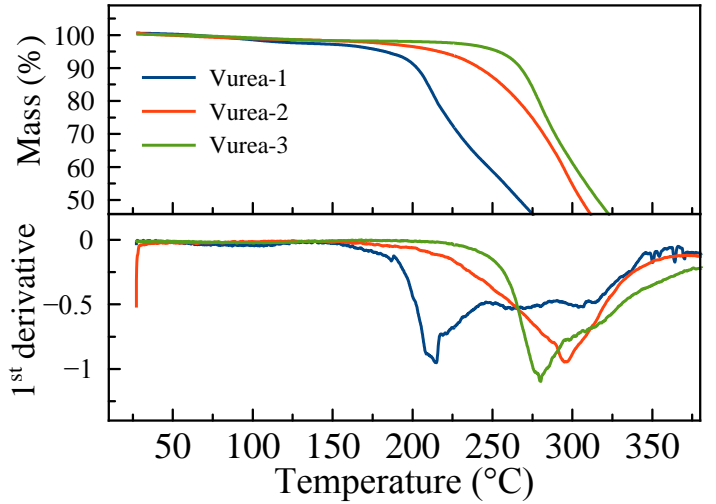

Figure 4. TGA-curve (top) and its first derivative (bottom) of different Vureas at $1^{\circ} \mathrm{C}$ min $^{-1}$.

In parallel, samples of the same material doped with 0.5 mol\% pTsOH catalyst were also investigated, as these are expected to show even faster exchanges. The obtained Vurea-3 materials, both with and without added pTsOH (0.5 mol\%) showed a similar glass transition at $110^{\circ} \mathrm{C}$ (DSC, Figure 5a), a storage modulus of around $2.2 \mathrm{GPa}$ at room temperature, and a DMA curve that confirms the $\mathrm{Tg}$ around $110^{\circ} \mathrm{C}$, followed by a rubbery plateau of $\sim 8 \mathrm{MPa}$ (DMA, Figure 5b), which is a typical DMA-behaviour for thermosets and indicates a constant cross-link density as expected for vitrimer materials. According to tensile tests, the Young's modulus was $\sim 1700 \mathrm{MPa}$ and the material failed at a stress of $\sim 64 \mathrm{Mpa}$ and an elongation of $\sim 6.4 \%$ (Figure 5c). Congruent with its vitrimer nature, the samples swelled, up to $305 \%$ in a good solvent such as NMP, but did not dissolve although they showed a considerable soluble fraction of $\sim 12 \%$ (Table S2, Supporting Information). Furthermore, it should be noted that the soluble fractions have been determined at temperatures of $100^{\circ} \mathrm{C}$ to provide enough solvent uptake and that small traces of water and amines had to be removed from NMP (with $\mathrm{MgSO}_{4}$ and silica respectively) to avoid a further increase of the soluble fraction (up to $20 \%$ ). In general, addition of $0.5 \mathrm{~mol} \% \mathrm{pTsOH}$ did not influence the Vurea material properties significantly as the variations are all within the expected measurement errors. The only distinct behaviour could be observed in the DMA-curve, where the catalysed sample showed a broader maximum in $\tan \delta$ and also an increasing value at higher temperatures. This increase in $\tan \delta$ upon heating can be explained by the fast exchange reactions that at the same time decrease the storage modulus and (slightly) increase the loss modulus.

Finally, also isothermal TGAs at $180^{\circ} \mathrm{C}$ of Vurea-3 (with or without $p \mathrm{Ts} \mathrm{OH}$ ) were recorded and showed a similar behaviour for both samples (Figure 5d). Surprisingly and in contrast to the TGA-measurement shown in Figure 4, an initial mass loss of $4 \%$ was observed. This initial weigh loss is caused by water evaporation as the samples were not stored dry and were measured after a week. The TGAmeasurement of freshly prepared samples, like those of Figure 4, indeed do not show this initial weight loss. The hygroscopic nature of the amine and amide functions in the repeating units of these materials thus needs to be taken into account for processing as a pre-drying step will be required to avoid blistering or formation of imperfections. However, water uptake is very common for all polymers capable of hydrogen bonding such as polyamides 
a)
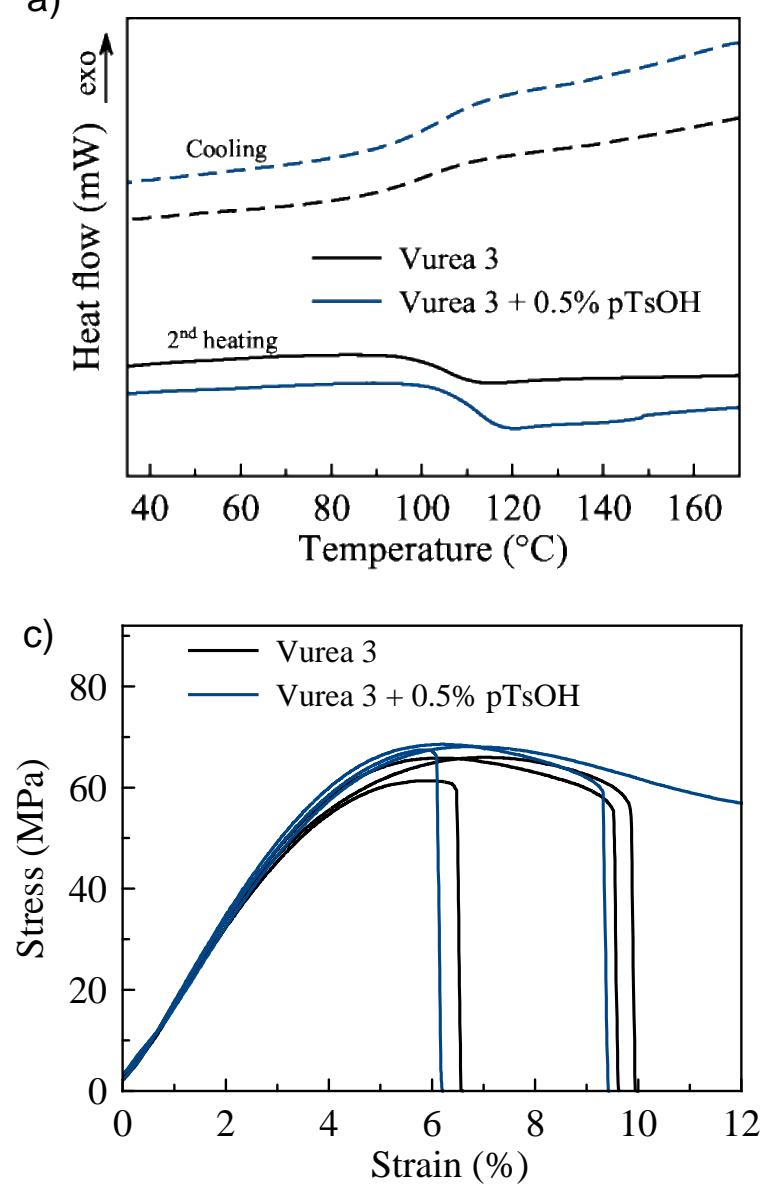

b)
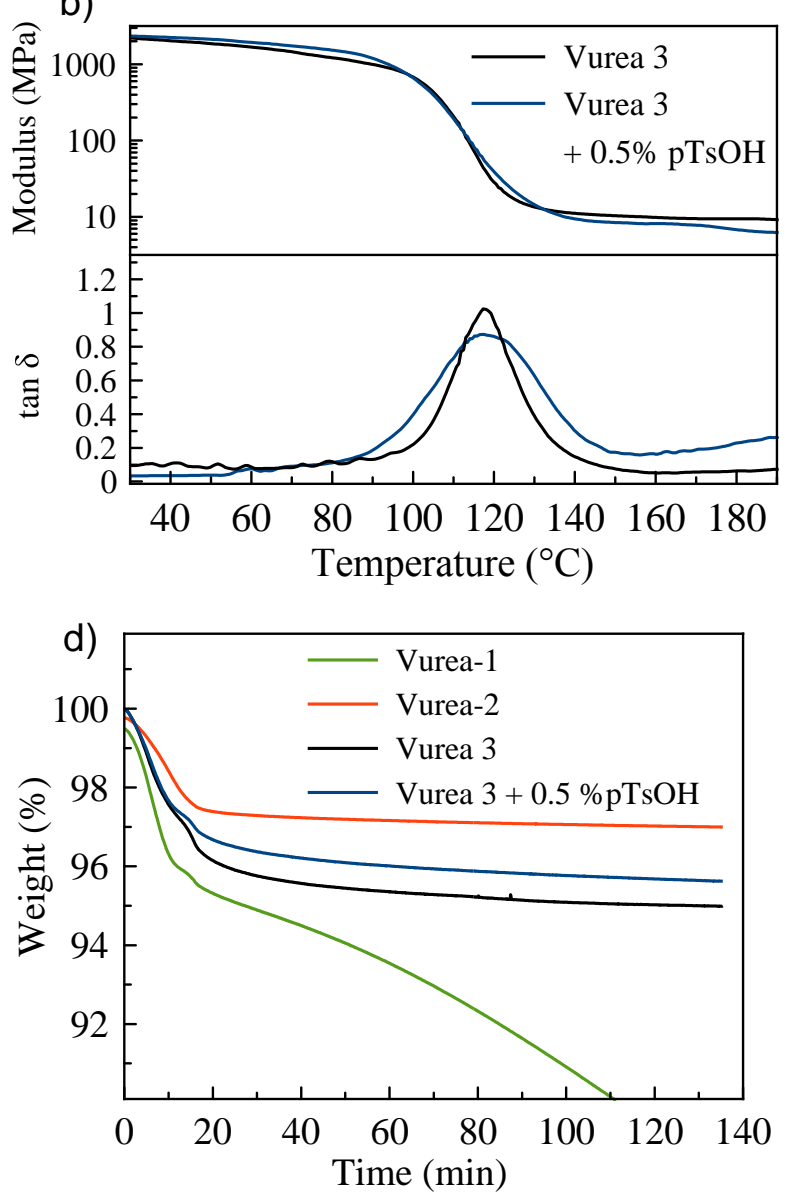

Figure 5: a) DSC thermogram of Vurea-3 and Vurea-3 with 0.5 mol\% pTsOH. b) DMA traces measured at $1 \mathrm{~Hz}$ in tension geometry. c) Tensile tests with a cross-head speed of $10 \mathrm{~mm} \mathrm{~min}^{-1}$. d) Isothermal TGA at $180^{\circ} \mathrm{C}$.

and polyurethanes and a drying step before processing is a standard industrial procedure for such type of plastics. The water uptake of Vurea-3 was quantified by immersing the material in water . After $24 \mathrm{~h}$, a mass increase of $8.5 \%$ was observed, further increasing to $11.7 \%$ after $48 \mathrm{~h}$.

Having established the mechanical properties of the high Tg Vurea-3 materials, their rheological behaviour was examined using frequency sweep experiments. In these measurements, the angular frequency was decreased from 100 rad.s $^{-1}$ to 0.001 rad.s ${ }^{-1}$ and they were ended when the cross-over of G' and G" was obtained. These experiments enable a measurement of relaxation times ranging from $0.01 \mathrm{~s}$ to $1000 \mathrm{~s}$.

In Figure 6, the results of the frequency sweep experiments of both Vurea-3 materials are presented. At high frequencies (i.e. short timescale), the storage modulus ( $\left.\mathrm{G}^{\prime}\right)$ dominates the loss modulus (G"), which means that the material behaves like a solid. However, when the frequency decreases, a cross-over of G' and G" can be observed. This cross-over indicates the transition of a solid-like behaviour to a liquid-like behaviour and allows to calculate the relaxation time as $\tau=1 / \omega$ (cross-over). As summarised in Table S3, Supporting Information, the measured relaxation times of the uncatalysed Vurea- 3 ranged from $132 \mathrm{~s}$ to $57 \mathrm{~s}$. To our surprise, these relaxation times are not that different from our previously reported vinylogous ure- thane networks $\left(85 \mathrm{~s}\right.$ at $\left.170^{\circ} \mathrm{C}\right),{ }^{12}$ even though model compounds showed an intrinsically much faster exchange in Vurea. Quite interestingly, however, the catalyst-doped Vurea samples showed very short relaxation times going from $13.9 \mathrm{~s}$ at $140^{\circ} \mathrm{C}$ to only $2.4 \mathrm{~s}$ at $170^{\circ} \mathrm{C}$, well below those observed in catalysed Vurethane vitrimers. As indicated in Table S3 (Supporting information), this corresponds to viscosities in the order of $10^{6} \mathrm{~Pa}$.s, suitable for processing that is normally reserved for thermoplastic materials. Characteristic for vitrimers, relaxation times followed the Arrhenius law and the activation energies of the samples were calculated as $44 \pm 4 \mathrm{~kJ} \mathrm{~mol}^{-1}$ and $45 \pm 8$ $\mathrm{kJ} \mathrm{mol}{ }^{-1}$ for the uncatalysed and catalysed Vurea- 3 respectively. These values are slightly lower than those measured for the model compounds ( $\left.49 \mathrm{~kJ} \mathrm{~mol}^{-1}\right)$, which could be explained by the more polar environment of the polymer matrix compared to the apolar solvent (benzene) used in the model compound study. 


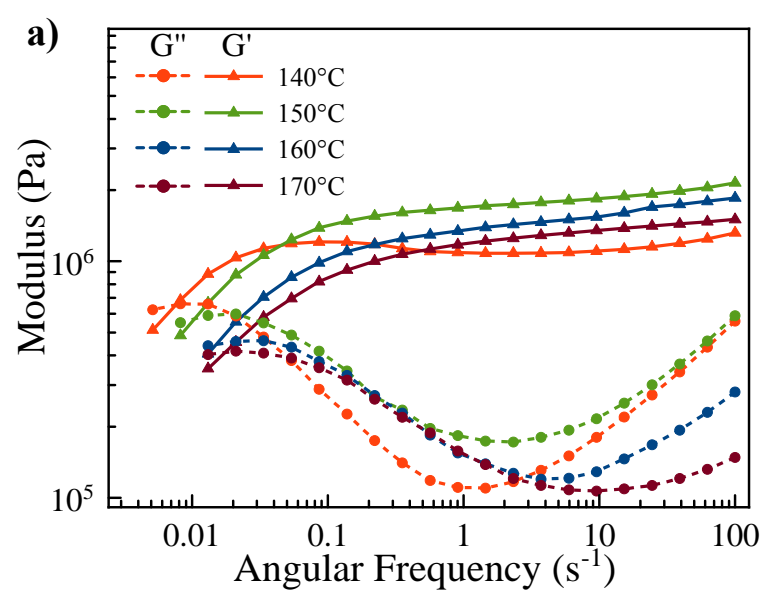

b)

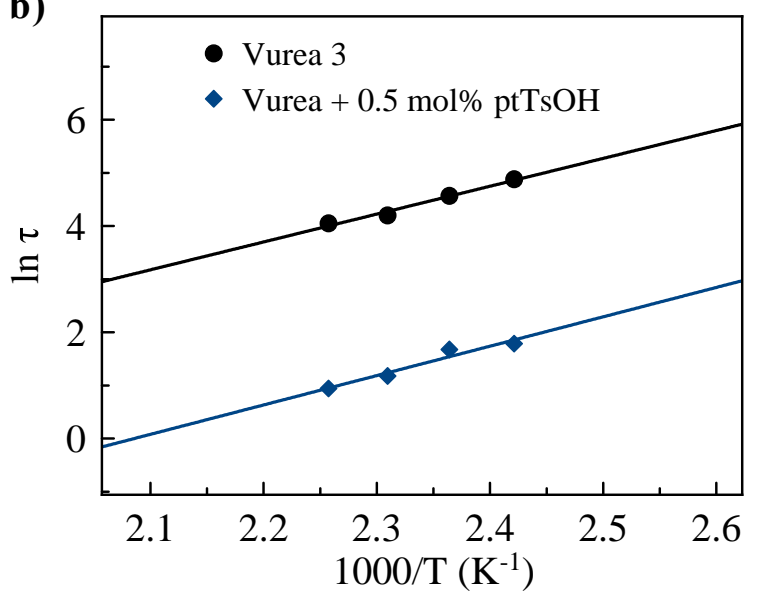

Figure 6. a) Frequency sweep experiments of Vurea-3 at different temperatures. b) Arrhenius plot of the measured relaxation times from the frequency sweep experiments.

As a further assessment of the dynamic properties of Vurea-3, the recyclability and processability of the catalyzed Vurea-3 was examined as these networks showed the shortest relaxation times. To investigate the recyclability, the catalyzed Vurea-3 was ground to powder, loaded into a pre-heated mould and compressed for 2, 5 or 10 minutes at $180^{\circ} \mathrm{C}$ or 30 minutes at $150^{\circ} \mathrm{C}$ (Figure S9a, Supporting Information). After the specified time, the samples were removed and cooled to room temperature. Already after compressing 2 minutes at $180^{\circ} \mathrm{C}$, a visually defectfree, transparent sample was obtained (Figure S9 b, Supporting Information). On the other hand, tensile tests showed that the materials that were compressed for five minutes exhibited the best mechanical properties with a stress- and strain-at-break of $85 \pm 2 \mathrm{MPa}$ and $5.7 \pm 0.4 \%$ respectively. Increasing the compression time to 10 minutes at $180^{\circ} \mathrm{C}$ or a longer time at lower temperature (30 minutes at $150^{\circ} \mathrm{C}$ ) did not improve the mechanical properties. Furthermore, repeating the grinding/compression cycle for a second time yielded materials with similar properties as shown in Figure S9c. Finally, to demonstrate the fast processability of the catalyzed Vurea3 , a disk shaped sample was put on a heated plate of $180^{\circ} \mathrm{C}$ and compressed for only one minute. As shown in Figure S9d, a transparent, flat film was obtained.

\section{Composites}

As outlined in the introduction, one of the applications where the unique properties of vitrimers can be an asset, is situated in the field of composites. While many procedures exist to prepare composites, one widely used method for high-end applications exploits prepregs or "preimpregnated" fibers. These prepregs are fibers where the matrix material, usually a thermosetting epoxy, is impregnated and only partially cured to the so-called B-stage. Next, several layers of these prepregs are applied in a mould and transformed to the desired multi-layer composite through combination of pressure and heat. Although this approach enables an easy one-time processing, the curing of the prepregs needs to be retained in a suspended but still chemically reactive state until final use, which results in a limited shelf-life and requires careful storage, transport at low temperatures and the use of special protective foils as the prepregs are often tacky.

Due to the inconveniences of thermosetting matrices for prepregs, thermoplastics are more and more used as alternative since they do not show the drawbacks of thermosetting B-stage prepregs. Yet, because of the absence of crosslinks, their resistance towards creep is not as good. By replacing partially-cured reactive thermosetting resins or thermoplastics as composite matrices with a vitrimer, a prepreg stable and inert under storage/transport conditions that is not tacky and remains processable should be obtained . In addition, such a vitrimer composite remains processable and even recyclable after its formation process and should have a creep resistance comparable to thermosets at service temperature. Vurea-based composites using a prepreg strategy are therefore presented and a proof-of-concept of vitrimer prepregs demonstrated below. Our strategy consists of first preparing fully cured single-layer prepregs, which will be transformed to a laminate via application of heat and pressure.

To obtain composite materials with good properties, we first explored a few alternative compositions for secondary amide-based Vurea materials, in addition to the initially studied one (Vurea-3). We arrived at a formulation (Vurea4) where the flexible 1,6-diamino hexane 9 was replaced by the more rigid $m$-xylylene diamine 10 (Figure 7), which resulted in improved material properties with a Young's modulus of $2221 \pm 17 \mathrm{MPa}$, strain at failure of $4.9 \pm 0.5 \%$ and stress at failure of $72 \pm 6 \mathrm{MPa}$. In addition, the Tg was increased to $127^{\circ} \mathrm{C}$, to be compared to $110{ }^{\circ} \mathrm{C}$ for Vurea-3. In order to obtain good fiber impregnation, the polymerization reaction is best carried out on the fibers. While the Vurea networks can be easily prepared from mixing monomers without solvent, this method does not enable a good fiber impregnation. As the viscosity rises extremely fast after mixing the monomers and gelation occurs within a couple of minutes, a solvent was added to slow down the fast cross-linking and gelation. Thus, acetoacetamide monomer $\mathbf{7}$ and the amine monomers $\mathbf{8}$ and $\mathbf{1 0}$ were dissolved separately in minimal amounts of solvent and only then mixed and immediately applied. 


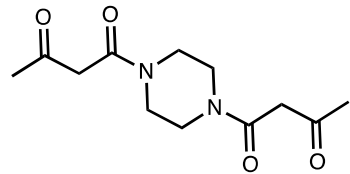

7

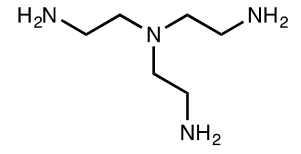

8

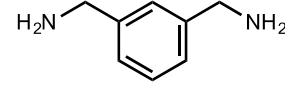

10
Figure 7. Monomers used to prepare Vurea-4 networks, which were used for the composite matrix.

Via this approach, gelation is effectively delayed and the viscosity remained low for a time interval that allows the manual impregnation of the fibers (Figure 8). For the complete and detailed procedure, we refer to the experimental section.
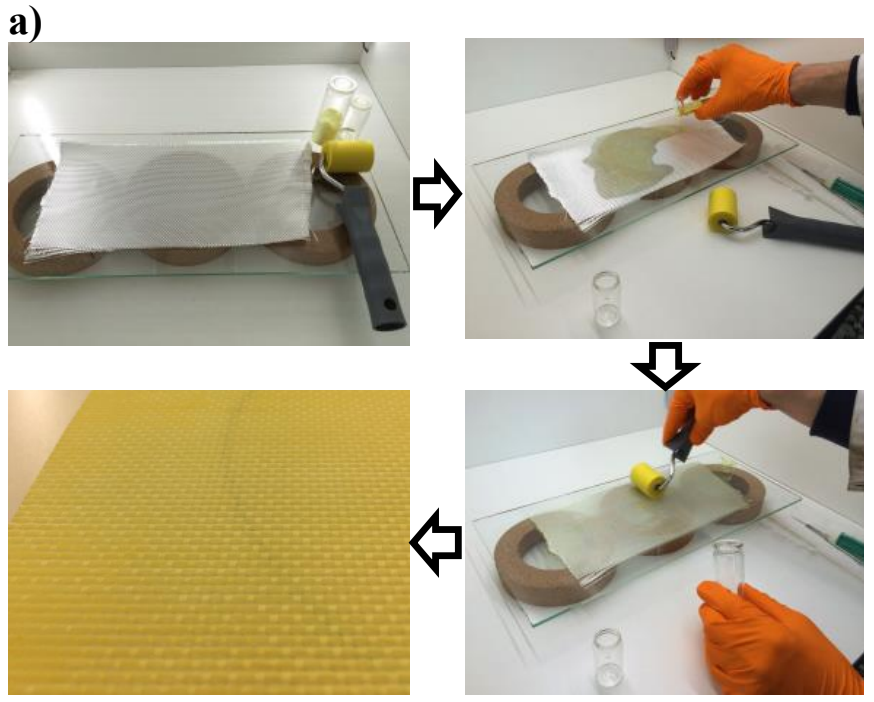

Figure 8. a) Pictures showing the manual impregnation process of glass fiber with diluted Vurea- 4 resin. b)

After a brief study using ethanol and methanol as solvent and different curing conditions, optimal conditions were found in methanol as solvent and a three-step curing process that consists of $30 \mathrm{~min}$ at $60^{\circ} \mathrm{C}, 30 \mathrm{~min}$ at $90^{\circ} \mathrm{C}$ and a post cure of $60 \mathrm{~min}$ at $170^{\circ} \mathrm{C}$ in vacuo. This post cure process resulted in the complete removal of methanol in a short timeframe (see Figure S10). With the optimised procedure that allowed good fiber impregnation and the production of solvent-free samples, we then set out to prepare completely cured single layer glass-fiber sheets. Multi- layer composites were prepared by simply stacking six single-layer Vurea composite sheets with their fiber alignment in the same direction (hereinafter denoted as $\left[0^{\circ}\right]_{6}$ ) and pressing them together using a heated hydraulic press.

In a first trial, unidirectional fibers were used and the layers were pressed together for 30 minutes at $150^{\circ} \mathrm{C}$ with a pressure of approximately 100 and 200 bar (3 and 6 metric tons on $28 \mathrm{~cm}^{3}$ ). In the samples compressed at 100 bar, the six layers are still clearly distinguishable with a significant amount of porosities visible in between the layers (Figure S11a, Supporting Information). Such voids are not desired as they have a detrimental effect on the mechanical properties of the composite laminates. ${ }^{28}$ Upon close inspection of the sectional profile images, it can be observed that the impregnation itself was successful as all fibers are fully surrounded by matrix (Figure S11 b, Supporting Information). Also some artefacts are visible (black spots), which either can be a porosity in the binder material or caused by the polishing of the samples to obtain a smooth surface for the microscope pictures. In the composite sample compressed at 200 bar, the different layers are less distinguishable and also fewer porosities remain (Figure S11c, Supporting Information). On the other hand, the close-up images show that the fibers are compressed so strongly that they are now in physical contact with each other. Such fiber contacts inhibit good load transfer from the matrix to the reinforcing fibers and is thus also undesired (Figure S11d, Supporting Information).

In the above experiments, it was also observed that the composite samples were pushed slightly open when applying pressure (lateral deformation). For this reason, the unidirectional fiber arrangement was changed to a partially unidirectional fabric (Warp/Weft 90/10). In addition, this fabric proved to be more resistant to fiber misalignment during the manual impregnation process. With the knowledge of previous experiments, samples were compressed using a pressure of 150 bar and the temperature and pressing time were increased to $170^{\circ} \mathrm{C}$ and $1 \mathrm{~h}$ to ensure full interlayer adhesion. These pressing conditions resulted in samples without any porosities and the different layers were only observable because of the transverse fibers (Figure 9a and b). Moreover, no defects or delamination could be observed. Based on TGA-measurements (i.e. resin burning-off method), a fiber volume fraction of $57 \%$ was obtained, which was slightly above the aimed value of $50 \%$ (Figure S12, Supporting Information). This fiber volume fraction approaches those used for more demanding applications (55-65\%). The obtained defect-free composites were subjected to tensile tests, in which three samples were loaded until failure in the direction of the fibers $\left(0^{\circ}\right)$. As depicted in figure $10 \mathrm{a}$, a good reproducibility of measured mechanical properties was observed. One sample proved to be slightly stiffer and showed a lower strain and strength to failure, which besides 

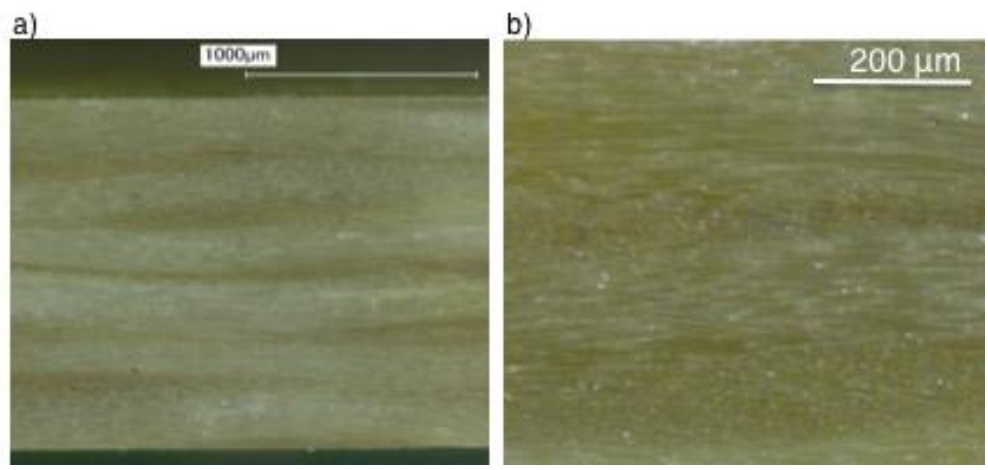

Figure 9. Microscope pictures of a woven-fiber composite via the compression of six completely cured prepregs $\left(170^{\circ} \mathrm{C}, 1 \mathrm{~h}, 150\right.$ bar) with a) complete cross-section of laminate and b) zoom-in of a.
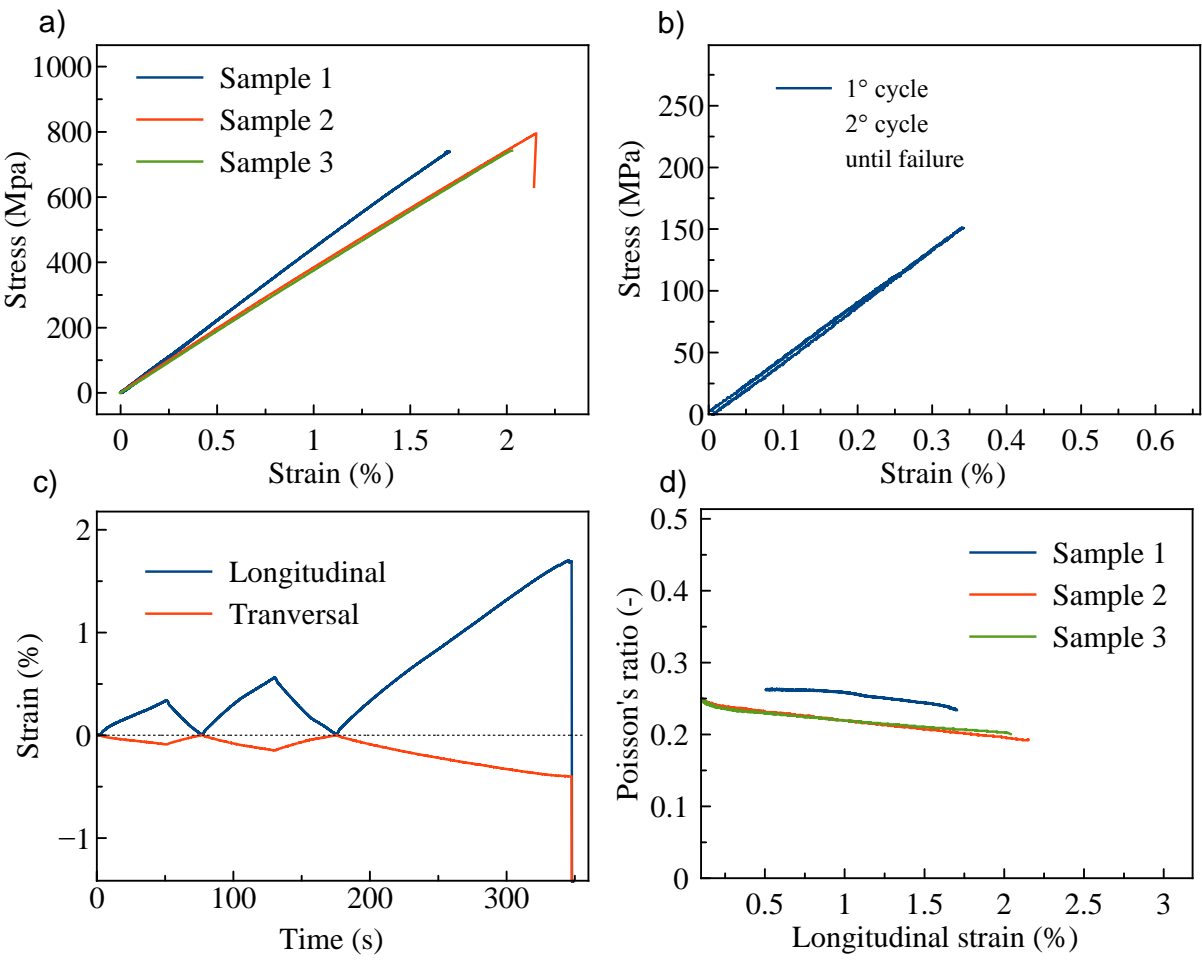

e)

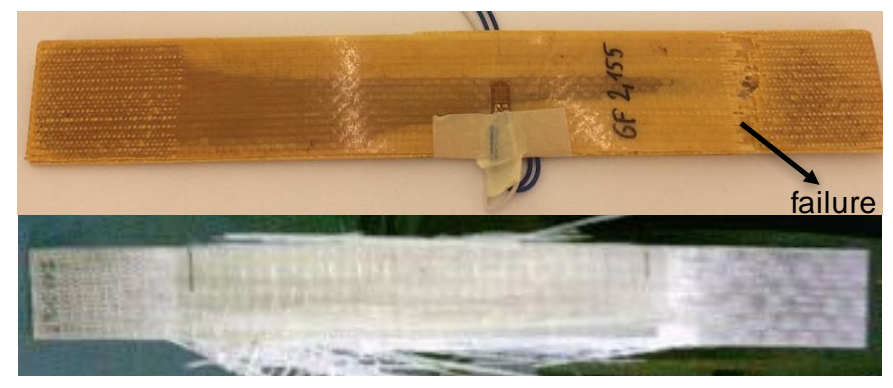

Figure 10. a) Stress-strain curves of Vurea composites. b) Zoom-in on the two loading-unloading cycles of sample 1. c) Strain as a function of time for two loading-unloading cycles followed by loading until failure. d) Poisson's ratio as a function of strain. e) The Vurea composite after tensile test shows that the failure occurred near the grips. f) Reference UD glass fabric reinforced epoxy $\left[0^{\circ}\right]_{8}$ after failure.

batch-to-batch differences could also be caused by a slight difference in stacking orientation. Since the samples consisted of six layers with a size of $(20 \times 3) \mathrm{cm}^{2}$, they were cut out from different batches of prepregs. These results thus indicate that the process of impregnation, followed by 
the compression to a laminate, allow producing samples with comparable/similar properties.

The mechanical properties of the prepared vitrimer composites are listed in Table 1 and compared to those of a similar epoxy laminate, ${ }^{29}$ showing a quite favourable match. This observation is quite promising as the epoxymatrix is a completely optimised formulation for composite resins. In addition, the examined samples all failed near the grips (Figure 10e), which means that the measured stress and strain at failure are underestimated. Interestingly, it was observed that the samples showed no visual damage before failure as the sample did not turn opaque. Even after failure, a large part of the sample remained free of visual cracks (see middle to left side of the composite material in Figure 10e), which is a markedly different behaviour compared to the epoxy reference that became completely opaque (Figure 10f). Moreover, no audible damage could be heard before failure, which occurs normally due to matrix cracking and the failure of individual fibers. The reasons for this different behaviour is currently unknown but will be part of future research.

For our first sample, two consecutive loading-unloading cycles were applied before a final loading until failure. As can be seen in Figure 10b and c, almost no hysteresis occurs as the laminate returns to its initial position after being strained and shows no visible deterioration of its stiffness. Congruent with the absence of opacity, this indicates that the laminate shows no measurable damage during these two loading cycles although small ruptures are in fact expected.

To demonstrate the post-curing processability of Vurea vitrimer composites, a two-layer composite $\left(\left[0^{\circ}\right]_{2}\right)$ was prepared according to the previously described method. This flat composite was then thermo-formed using a preheated mould at $150^{\circ} \mathrm{C}$ (Figure 11). In order to achieve thermoforming, the composite bilayer was first positioned in the pre-heated mold and thermally equilibrated for several minutes to ensure that the composite is at $150^{\circ} \mathrm{C}$, well above its Tg. Next, the pressure was increased gradually to push the die in the composite

Table 1. Measured mechanical properties of a Vureabased composite. For comparison, the values of a similar epoxy laminate are shown. ${ }^{29}$

\begin{tabular}{llcc}
\hline & $\begin{array}{l}\text { Vurea composite } \\
{\left[0^{\circ}\right]_{6}}\end{array}$ & $\begin{array}{l}\text { UD glass fabric rein- } \\
\text { forced } \\
{\left[0^{\circ}\right]_{8}}\end{array}$ & $\begin{array}{c}\text { epoxy } \\
\mathrm{E}_{11}(\mathrm{GPa})\end{array}$ \\
$\mathrm{X}_{\mathrm{t}}(\mathrm{MPa})$ & $70.2 \pm 3.0$ & 42 \\
$\varepsilon_{11}(\%)$ & $1.9 \pm 0.2$ & 939 \\
$v_{12}(-)$ & $0.249 \pm 0.015$ & 2.5 \\
\hline
\end{tabular}

$\mathrm{X}_{\mathrm{t}}=$ Strain at failure, $\varepsilon_{11}=$ elongation at failure, $v=$ Poisson's ratio

without damaging the fibers, after which the composite was kept for about five minutes in this shape to allow for the reorganisation of the vitrimer matrix. Finally, the upper part of the die was removed and the composite retained its shape, even when it was still well above its $\mathrm{T}_{\mathrm{g}}$. After cooling, a shaped composite was obtained without visual defects besides those in the corners of the triangle due to excessive deformation of the fibers.

As a final point of interest, the ability to chemically recycle the fibers was also tested with these vitrimer composites. In this context, a single-layer Vurea composite was partially immersed in $\mathrm{N}$-methylpyrrolidone (NMP) or a solution of NMP with a primary amine (Figure S13a, Supporting Information).

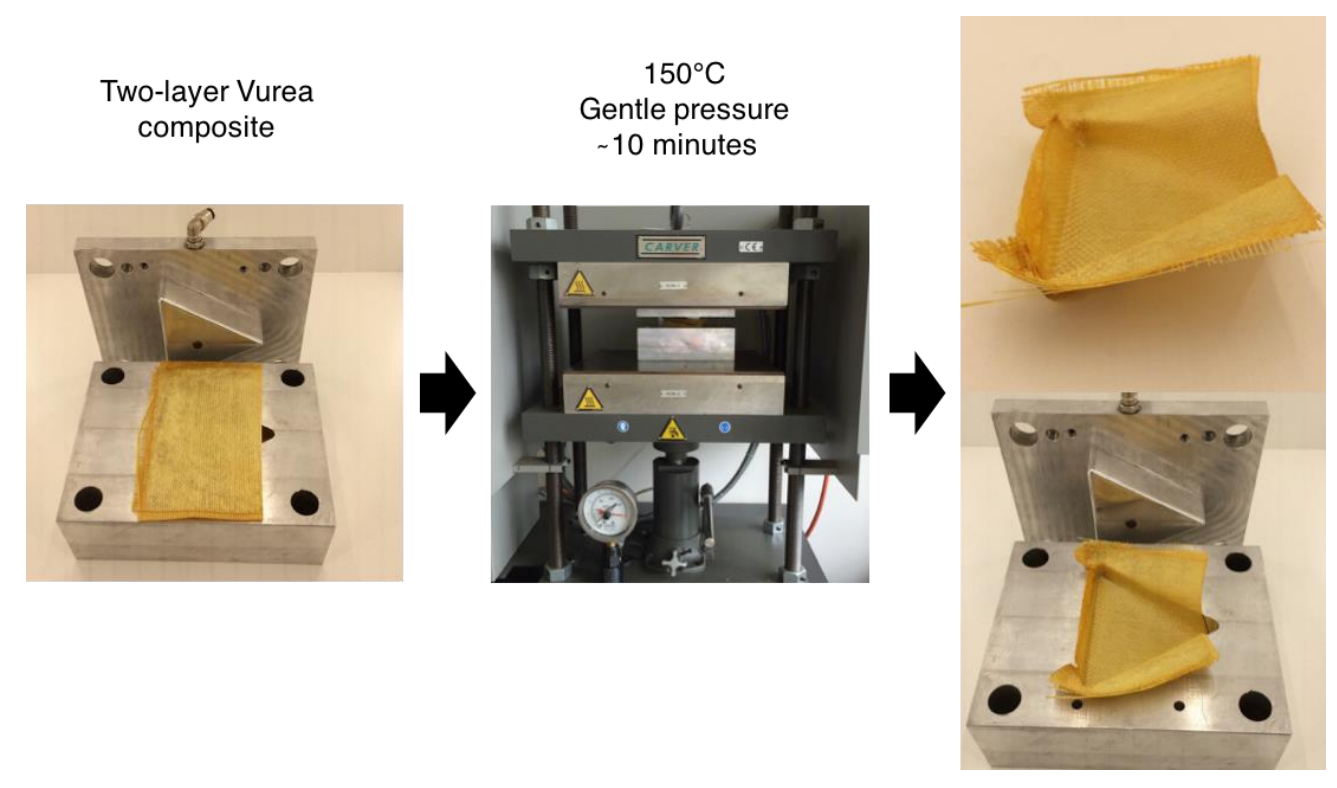

Figure 11. Thermoforming of a flat Vurea composite into a triangular shape. 
As this amine can induce the same exchange reactions, its incorporation in the network bonds will lead to a depolymerisation reaction, and the matrix should be easily removed from the glass fiber fabric (Figure S13 b, Supporting Information). Indeed, only 15 minutes at $100^{\circ} \mathrm{C}$ resulted in a visually complete removal of the matrix (Figure S13c, Supporting Information). On the other hand, the reference without amine did not dissolve, even after $20 \mathrm{~h}$ at $100^{\circ} \mathrm{C}$. At room temperature, the same results were achieved after $6 \mathrm{~h}$, as the swelling of the matrix allows chain mobility and thus exchange to take place below the Tg of the network (Figure S13d, Supporting Information). This preliminary test clearly shows the opportunities for the easy recycling of fibers from composites using this promising vitrimer matrix.

\section{Conclusion}

We explored different vinylogous acyl compounds and found that secondary vinylogous urea exhibit the fastest intrinsic exchange kinetics, which can be even further enhanced by addition of simple acid catalyst. Capitalizing on this swift exchange reaction, poly(vinylogous) urea vitrimers were prepared and showed good mechanical properties ( $\left(\mathrm{Tg} \sim 110^{\circ} \mathrm{C}, \mathrm{E} \sim 2.2 \mathrm{GPa}, \sigma \sim 70 \mathrm{MPa}\right)$ together with relaxation times in the order of seconds when heated $20^{\circ} \mathrm{C}$ above its glass transition. These vinylogous urea vitrimers were exploited as a matrix for composite materials and enabled enduring prepregs that still allow an efficient thermal fusion of multiple layers as well as thermoforming and fiber recycling by solvolysis.

\section{Experimental section \\ Instrumentation}

Nuclear magnetic resonance spectra were recorded on a Bruker Avance 300 or a Bruker Avance II 700 spectrometer at room temperature. IR spectra were collected using a Perkin-Elmer Spectrum1000 FTIR infrared spectrometer with a diamond ATR probe. Thermogravimetric analyses were performed with a Mettler Toledo TGA/SDTA851e instrument under air or nitrogen atmosphere. Differential scanning calorimetry (DSC) analyses were performed with a Mettler Toledo instrument 1/700 under nitrogen atmosphere at a heating rate of $10^{\circ} \mathrm{C} \mathrm{min}-1$. Dynamic mechanical analysis (DMA) was performed on a SDTA861e DMA from Mettler Toledo, in tension geometry at $1 \mathrm{~Hz}$, dual controlled by a displacement amplitude of $15 \mu \mathrm{m}$ or Force amplitude of $10 \mathrm{~N}$ with a typical sample size of $(22 \times 4 \mathrm{x}$ 1.5) $\mathrm{mm}^{3}$. Samples were processed using a custom-made mould and a Carver manual press model 4122.

Frequency sweep experiments were performed on an Anton-Paar physica MRC 301 rheometer with a plate geometry of $25 \mathrm{~mm}$, an amplitude of $0.1 \%$, which is within the linear viscoelastic region according to an amplitude sweep experiment, the frequency was changed from 100 $\mathrm{rad} \mathrm{s}^{-1}$ to $2.10^{-3} \mathrm{rad} \mathrm{s}^{-1}$ and a normal force of $10 \mathrm{~N}$ was used.

Tensile testing of polymer samples was performed on a Tinius-Olsen H10KT tensile tester, equipped with a $100 \mathrm{~N}$ load cell, using a flat dog bone type specimen with an effective gauge length of $13 \mathrm{~mm}$, a width of $2 \mathrm{~mm}$, and a thick- ness of $1.3 \mathrm{~mm}$. The samples were cut out using a Ray-Ran dog bone cutter. The tensile tests were run at a speed of 10 $\mathrm{mm} / \mathrm{min}$. The tensile tests of composites were performed on a servo-hydraulic INSTRON 8801 tensile testing machine with a FastTrack 8800 digital controller and a load cell of $\pm 100 \mathrm{kN}$ (Department of Materials Science and Engineering, UGent). The quasi-static tests were displacementcontrolled with a speed of $2 \mathrm{~mm} / \mathrm{min}$. A special fixture is mounted on the tensile machine to prevent relative rotation of the grips, causing torsion of the specimen. Alignment of the grips was established using an INSTRON alignment kit. For the registration of the tensile data, a National Instruments C-series data acquisition card was used. The load, displacement and strain, given by the FastTrack controller as well as the extra signals from strain gauges were sampled on the same time basis. The used samples got a rectangular shape of $(3 \times 20) \mathrm{cm}^{2}$.

Microscope pictures of the composites were obtained using a Dinolite AM411 or Keyence VHX-200 HDR microscope.

\section{Materials}

Tris(2-aminoethyl)amine (96\%), butylamine ( $\geq 99 \%), 1$ phenyl-1,3-butadione (99\%), $m$-xylylene diamine ( $\geq 99 \%)$, 2,2,6-trimethyl-4H-1,3-dioxin-4-one (95\%), 1,6diaminohexane (98\%), ethylenediamine- $\mathrm{N}, \mathrm{N}^{\prime}$ bis(acetoacetamide) and tert-butyl acetoacetate ( $\geq 98 \%)$ were purchased from Sigma Aldrich. Piperazine (>98\%) and 1,4-phenylenediamine (>98\%) were purchased from TCI chemicals. Glass-fiber fabric style 3025 was used from Porcher industries.

Synthesis of $N, N^{\prime}$-(ethane-1,2-diyl)bis(3-(butylamino)but2-enamide and N,N'-(ethane-1,2-diyl)bis(3(benzylamino)but-2-enamide)

$N, N^{\prime}$-(ethane-1,2-diyl)bis(3-oxobutanamide) (1 equiv., 1 g) and butylamine (2 equiv.) or benzylamine (2 equiv.) were mixed in $20 \mathrm{~mL}$ water and stirred for $6 \mathrm{~h}$ at room temperature. The white precipitate was filtered, washed with water $(3 \times 10 \mathrm{~mL})$ and dried in vacuo yielding $\mathrm{N}, \mathrm{N}^{\prime}$ (ethane-1,2-diyl)bis(3-(butylamino)but-2-enamide or the corresponding $N, N^{\prime}$-(ethane-1,2-diyl)bis(3(benzylamino)but-2-enamide) both as a white powder.

Yield N,N'-(ethane-1,2-diyl)bis(3-(butylamino)but-2enamide: $\quad 95 \%$ ${ }^{1} \mathrm{H}$ NMR (300 MHz, benzene-d6) $\delta(\mathrm{ppm})=9.55(\mathrm{br} \mathrm{s}, 2 \mathrm{H}$, 2x $\mathrm{NHCH=),} 5.47$ (br s, 2H, 2x NHCO), 4.28 (s, 2H, 2xCH=), $3.32\left(4 \mathrm{H}\right.$, br s, $\left.-\mathrm{NHCH}_{2} \mathrm{CH}_{2} \mathrm{NH}-\right), 2.72$ (4H, app. q, $J \cong 6.4 \mathrm{~Hz}$, $\left.2 \mathrm{x}-\mathrm{CH}_{2} \mathrm{CH}_{2} \mathrm{NHC}=\right), 1.52\left(6 \mathrm{H}, \mathrm{s}, \mathrm{CH}_{3} \mathrm{C}=\right), 1.19$ (band, 8H, $\left.\mathrm{CH}_{2}-\right), 0.73\left(\mathrm{t}, \mathrm{J}=7.2 \mathrm{~Hz}, 6 \mathrm{H}, \mathrm{CH}_{3}-\mathrm{CH}_{2-}\right)$

Yield N,N'-(ethane-1,2-diyl)bis(3-(benzylamino)but-2enamide): $93 \%$

${ }^{1} \mathrm{H}$ NMR (300 MHz, benzene-d6): $\delta(\mathrm{ppm})=10.00(\mathrm{br} \mathrm{s}, 2 \mathrm{H}$, 2x $\mathrm{NHCH=),} \mathrm{7.08-5.98} \mathrm{(band,} \mathrm{8H,} \mathrm{CH}_{\mathrm{ar}}$ ), 5.23 (br s, 2H, 2x $\mathrm{NHCO}), 4.24(\mathrm{~s}, 2 \mathrm{H}, 2 \mathrm{xCH}=), 3.86\left(\mathrm{~d}, J=6.68,4 \mathrm{H}, \mathrm{PhCH}_{2} \mathrm{NH}-\right.$ ), 3.27 (br s, $4 \mathrm{H},-\mathrm{NHCH}_{2} \mathrm{CH}_{2} \mathrm{NH}-$ ), $1.44\left(\mathrm{~s}, 6 \mathrm{H}, \mathrm{CH}_{3} \mathrm{C}=\right.$ )

\section{Synthesis of 1-(3-oxobutanoyl) piperidine}

2,2,6-Trimethyl-4H-1,3-dioxin-4-one (1 equiv., $5.0 \mathrm{~g}$ ) and piperidine (1.1 equiv., $3.29 \mathrm{~g}$ ) were mixed in $7 \mathrm{~mL}$ xylene and heated for $30 \mathrm{~min}$ at $150^{\circ} \mathrm{C}$ in a preheated oil 
bath. The solvent, excess piperidine and released acetone were removed in vacuo yielding the desired product as a viscous oil (yield $=99 \%$ ).

1H NMR (300MHz, CDCl3) $\delta(\mathrm{ppm})=3.48-3.26$ (band, 6 $\mathrm{H}), 2.4-2.75$ (band, 6H), $2.19(\mathrm{~s}, 3 \mathrm{H})$. In accordance with the product prepared by Shridharan et al. ${ }^{30}$

Synthesis of 3-(butylamino)-1-(piperidin-1-yl)but-2-en-1one and 3-(benzylamino)-1-(piperidin-1-yl)but-2-en-1-one

Piperide acetoacetamide (1 equiv., $1 \mathrm{~g}$ ) and butylamine (1.5 equiv., $0.646 \mathrm{~g}$ ) or benzylamine (1 equiv., $0.633 \mathrm{~g}$ ) were mixed in $5 \mathrm{~mL} \mathrm{MeOH}$ and stirred overnight. The solvent was removed in vacuo and the mixture was extracted twice with DCM/water. The combined organic fases were dried with $\mathrm{MgSO}_{4}$, filtered and the solvent was evaporated yielding the desired product as a viscous oil.

Yield 3-(butylamino)-1-(piperidin-1-yl)but-2-en-1-one: 93\%. 1H NMR (300MHz, CDCl3) $\delta(\mathrm{ppm})=9.52$ (br s, $1 \mathrm{H}$, $\mathrm{NH}), 4.50(\mathrm{~s}, 1 \mathrm{H},=\mathrm{CH}), 3.45\left(\mathrm{t}, \mathrm{J}=5.3 \mathrm{~Hz}, 4 \mathrm{H}, \mathrm{NCH} \mathrm{N}_{2}\right), 3.18$ (txd, J=7.0 and $5.9 \mathrm{~Hz}, 2 \mathrm{H},-\mathrm{NH}-\mathrm{CH}_{2}-$ ), $1.92\left(\mathrm{~s}, 3 \mathrm{H}, \mathrm{CH}_{3} \mathrm{C}=\right.$ ), 1.60-1.51 (band, 8H, 2 x ring $\mathrm{CH}_{2}+\mathrm{CH}_{3} \mathrm{CH}_{2} \mathrm{CH}_{2} \mathrm{CH}_{2} \mathrm{NH}-$ ), $1.42\left(\mathrm{~m}, 2 \mathrm{H}\right.$, ring $\left.\mathrm{CH}_{2}\right), 0.93\left(\mathrm{t}, J=7.2 \mathrm{~Hz}, 3 \mathrm{H}, \mathrm{CH}_{3} \mathrm{CH}_{2}-\right) \cdot{ }^{13} \mathrm{C}$ NMR(75Mhz, $\left.\mathrm{CDCl}_{3}\right) \delta(\mathrm{ppm})=169.9(\mathrm{C}), 159.6(\mathrm{C}), 80.6$ $(\mathrm{CH}), 47.8\left(\mathrm{CH}_{2}\right), 42.2\left(\mathrm{CH}_{2}\right), 32.6\left(\mathrm{CH}_{2}\right), 26.1\left(\mathrm{CH}_{2}\right), 24.9$ $\left(\mathrm{CH}_{2}\right), 20.1\left(\mathrm{CH}_{2}\right), 20.0\left(\mathrm{CH}_{3}\right), 13.8\left(\mathrm{CH}_{3}\right)$. HRMS $(\mathrm{m} / \mathrm{z}$ for [MH]+): calculated:225.1961, experimental: 225.1968

Yield 3-(benzylamino)-1-(piperidin-1-yl)but-2-en-1-one: 91\%. 1H NMR (300MHz, CDCl3) $\delta(\mathrm{ppm})=9.95(\mathrm{br} \mathrm{s}, 1 \mathrm{H})$, 7.22-7.37 (5H, band), $4.72(1 \mathrm{H}, \mathrm{d}, J=0.6 \mathrm{~Hz}), 4.42(\mathrm{~d}, 2 \mathrm{H}, J$ $=6.45 \mathrm{~Hz}), 3.48(\mathrm{t}, 4 \mathrm{H}, J=5.23 \mathrm{~Hz}), 1.92(\mathrm{~d}, 3 \mathrm{H}, J=0.6 \mathrm{~Hz})$, $1.54-1.68$ (band, 6H).

Synthesis of 3-(benzylamino)-1-phenylbut-2-en-1-one and 3-(butylamino)-1-phenylbut-2-en-1-one

Benzoyl acetone (1.5 g, $9.25 \mathrm{mmol})$ and butylamine (1.83 mL, $18.5 \mathrm{mmol})$ or benzyl amine $(2 \mathrm{~mL}, 18.5 \mathrm{mmol})$ were mixed in $10 \mathrm{~mL} \mathrm{MeOH}$ and stirred overnight at room temperature after which full conversion was observed with TLC ( $\mathrm{rf}=0.36 \mathrm{EtOAc/hept} \mathrm{20/80).} \mathrm{The} \mathrm{solvent} \mathrm{was}$ removed in vacuo and filtered over a short column of silica to remove the excess of amine.

Yield 3-(benzylamino)-1-phenylbut-2-en-1-one: 81\% ${ }^{1} \mathrm{H}$ NMR (300 MHz, $\mathrm{CDCl}_{3}$ ): $1 \mathrm{H}$ NMR (400 MHz, CDCl3): $\delta(\mathrm{ppm})=11.75(\mathrm{~s}, 1 \mathrm{H}), 7.98-7.75(\mathrm{~m}, 2 \mathrm{H}), 7.51-7.16(\mathrm{~m}$, $8 \mathrm{H}), 5.75(\mathrm{~s}, 1 \mathrm{H}), 4.54(\mathrm{~d}, J=6.3 \mathrm{~Hz}, 2 \mathrm{H}), 2.07(\mathrm{~s}, 3 \mathrm{H})$. In agreement with ${ }^{31}$.

Yield 3-(butylamino)-1-phenylbut-2-en-1-one: $83 \%$ ${ }^{1} \mathrm{H}$ NMR (300 MHz, $\left.\mathrm{CDCl}_{3}\right): \delta(\mathrm{ppm})=11.5$ (br s, $\left.1 \mathrm{H}\right), 7.90-$ 7.86 (band, 2H), 7.43-7.40 (band, 3H), 5.58 (s, 1H), 3.34 $(\mathrm{td}, J=6.89 ; 5.92 \mathrm{~Hz}), 2.09(\mathrm{~s}, 3 \mathrm{H}), 1.71-1.62(\mathrm{~m}, 3 \mathrm{H}), 1.52-$ $1.44(\mathrm{~m}, 2 \mathrm{H}), 0.98(\mathrm{t}, J=7.27 \mathrm{~Hz}, 3 \mathrm{H})$. In agreement with ${ }^{31}$.

Kinetics exchange reaction N,N'-(ethane-1,2-diyl)bis(3(butylamino)but-2-enamide and benzylamine

Benzylamine $(0.25 \mathrm{mmol}, 26 \mathrm{mg})$ was added to a solution of N,N'-(ethane-1,2-diyl)bis(3-(butylamino)but-2enamide ( $0.05 \mathrm{mmol}, 8.15 \mathrm{mg}$ ) i.e. the $\mathrm{N}$-butyl vinylogous urea model compound in benzene-d6 $(0.79 \mathrm{~mL})$. Five equivalents of benzylamine versus the vinylogous urea groups were used to obtain a pseudo-first order reaction at low conversions. The mixture was kept at $10^{\circ} \mathrm{C}, 20^{\circ} \mathrm{C}$ and $30^{\circ} \mathrm{C}$ in a NMR-tube and spectra were taken on-line at different time intervals. The reaction was followed by integration of the apparent quadruplet signal at $2.72 \mathrm{ppm}$ of the butyl compound and the triplet signal at $3.86 \mathrm{ppm}$ of the benzyl compound.

Kinetics exchange reaction 3-(butylamino)-1-phenylbut-2en-1-one and benzylamine

Benzylamine (2.3 mmol, $246 \mathrm{mg}$ ) was added to a solution of 3-(butylamino)-1-phenylbut-2-en-1-one i.e. the $\mathrm{N}$ butyl vinylogous amide model compound ( $0.46 \mathrm{mmol}, 100$ $\mathrm{mg}$ ) in xylenes $(7.54 \mathrm{~mL})$. Five equivalents of benzylamine versus the vinylogous amide groups were used to obtain a pseudo-first order reaction at low conversions. The mixture was kept at $130^{\circ} \mathrm{C}, 150^{\circ} \mathrm{C}$ and $170^{\circ} \mathrm{C}$ in a pressuretube and GC analysis was performed different time intervals. The reaction was followed by integration of the FIDsignals at $6.7 \mathrm{~min}$ and at $7.45 \mathrm{~min}$ for the butyl- and benzyl model compound respectively. The integrated signals were corrected using a calibration curve for both compounds to take a different molar response factor in account. GC was performed on an Agilent 7890A system equipped with a VWR Carrier-160 hydrogen generator and an Agilent HP-5 column of $30 \mathrm{~m}$ length and $0.320 \mathrm{~mm}$ diameter. A FID detector was used and the inlet was set to $250^{\circ} \mathrm{C}$ with a split injection of ratio $25: 1$. Hydrogen was used as carrier gas at a flow rate of $2 \mathrm{~mL} / \mathrm{min}$. The oven temperature was increased with $20^{\circ} \mathrm{C} / \mathrm{min}$ from $50^{\circ} \mathrm{C}$ to $120^{\circ} \mathrm{C}$, followed by a ramp of $50^{\circ} \mathrm{C} / \mathrm{min}$. to $300^{\circ} \mathrm{C}$ and $5 \mathrm{~min}$ isothermal at $300^{\circ} \mathrm{C}$.

\section{Synthesis of N,N'-(1,4-phenylene)bis(3-oxobutanamide) 6}

A solution of tert-butyl acetoacetate (21.0 mmol, $3.38 \mathrm{~g})$ in xylene $(50 \mathrm{~mL})$ was heated to $140^{\circ} \mathrm{C}$ (internal temperature) with magnetically stirring. After 10 minutes, a solution of 1,4 phenylene diamine $(10 \mathrm{mmol})$ in xylene (100 $\mathrm{mL}$ ) was added dropwise using an addition funnel over a time course of $10 \mathrm{~min}$. After addition, stirring was continued for 1 hour at $140^{\circ} \mathrm{C}$ (internal temperature). Afterwards, xylenes was removed in vacuo affording a pale yellow precipitate. The solids were then redissolved in ethyl acetate $(50 \mathrm{~mL})$ to which hexane was added dropwise until the solution started to become cloudy. At this point, the solution was left at room temperature for a minimum of 12 hours. The obtained white solids were filtered off and dried in vacuo $\left(40^{\circ} \mathrm{C}\right)$, yielding the pure bisacetoacetamide 6 .

Yield: $50 \% .{ }^{1} \mathrm{H}$ NMR ((DMSO-d6), $\left.300 \mathrm{MHz}\right) \delta(\mathrm{ppm})$ : $10.80\left(\mathrm{~s}, 2 \mathrm{H}, \mathrm{N}_{\mathrm{H}}\right), 7.50\left(\mathrm{~s}, 4 \mathrm{H}, \mathrm{CH}_{\mathrm{ar}}\right), 3.55(\mathrm{~s}, 4 \mathrm{H}, \mathrm{COCH} 2 \mathrm{CO})$, 2.22 (s, 6H, COCH3).

\section{Synthesis of 1,4-(piperazine)bis(acetoacetamide) 7}

This compound was prepared as described by Trumbo et al. ${ }^{32}$ Piperazine (100 g, $1.16 \mathrm{~mol}$ ) and tert-butyl acetoacetate (385 g, $2.44 \mathrm{~mol})$ were refluxed in xylenes $(300 \mathrm{~mL})$ for $3 \mathrm{~h}$ with distillative removal of tert-butanol. The xylenes was removed in vacuo yielding an orange oil that crystallised upon standing. The obtained orange solid was redissolved in boiling acetone, cooled to room temperature and diethyl ether was added until a haziness was observed. This solution was stored overnight at $0^{\circ} \mathrm{C}$ resulting in the 
formation of white crystals, which were filtered and washed with cold diethyl ether yielding 7 as a white powder.

yield: 61\%. ${ }^{1} \mathrm{H}$ NMR ((DMSO-d6), $\left.500 \mathrm{MHz}\right) \delta(\mathrm{ppm}): 3.68$ (ss, $4 \mathrm{H},-\mathrm{C}(=\mathrm{O})-\mathrm{CH}_{2}-\mathrm{C}(=\mathrm{O})-$ ), 3.47-3.42 (m, 4H, $\mathrm{CH}_{\text {ring }}$ ), 3.35 $-3.31\left(\mathrm{~m}, 4 \mathrm{H}, \mathrm{CH}_{\text {ring }}\right), 2.16\left(\mathrm{~s}, 6 \mathrm{H}, \mathrm{CH}_{3} \mathrm{C}(=0)-\right)$.

\section{Representative synthesis of the Vurea networks}

1,6-Hexane diamine (1.824 g, $16.6 \mathrm{mmol})$ and TREN (2.241 g; $16.6 \mathrm{mmol}$ ) ) were weighed in a vial, heated in an oil bath to $80^{\circ} \mathrm{C}$ and 1,1'-(piperazine-1,4-diyl)bis(butane1,3-dione)) (Piperazine Aam) (10.0 g; 39,3 mmol) was added in bulk while manually stirring. When a fully homogenous mixture was obtained, the mixture was poured on a Teflon sheet and cured for $3 \mathrm{~h}$ in vacuo at $150^{\circ} \mathrm{C}$ yielding a hard glassy yellowish polymer. The conversion of acetoacetamide groups to the corresponding vinylogous urea was confirmed via ATR-IR by the disappearance of the $\mathrm{C}=0$ signal at $1711 \mathrm{~cm}^{-1}$ and the good agreement with the IR spectrum of the corresponding model compound, i.e. 3-(butylamino)-1-(piperidin-1-yl)but-2-en-1-one. The obtained, fully cured network was ground to a fine powder and mould pressed for $30 \mathrm{~min}$ at $150^{\circ} \mathrm{C}$ after which a homogeneous, defect-free sample was obtained that was used for further characterization.

The other polymer networks were prepared in the same fashion using the amounts shown in table 2 .

Table 2: Used stoichiometry and amounts for the preparation of different polymer networks.

\begin{tabular}{clccc}
\hline Network & Reagent & Eq & $\begin{array}{c}\mathbf{n} \\
\mathbf{( m m o l )}\end{array}$ & $\begin{array}{c}\text { Mass } \\
\mathbf{( g )}\end{array}$ \\
\hline Vurea 1 & Bis acetoacetamide & 0.95 & 43.8 & 10.000 \\
& TREN & 0.42 & 19.4 & 2.833 \\
& 1,6-hexane diamine & 0.39 & 17.5 & 2.036 \\
& water & & & 3.5 \\
\hline Vurea 2 & Acetoacetamide & 0.95 & 11.3 & 4.500 \\
& TREN & 0.40 & 6.9 & 1.003 \\
& m-xylylene diamine & 0.40 & 6.9 & 0.797 \\
& DMF & & & 4.0 \\
\hline Vurea 3 & Acetoacetamide & 0.95 & 39.4 & 10.000 \\
& TREN & 0.40 & 16.6 & 2.421 \\
& 1,6-hexane diamine & 0.40 & 16.6 & 1.924 \\
\hline
\end{tabular}

\section{Preparation of a single-layer Vurea composite}

One layer of glass fibre (24.5 g) was taped on a glassplate (no releasing agent was used) and heated to $50^{\circ} \mathrm{C}$ in an oven. 1,4-(piperazine)bis(acetoacetamide) (7 g, 27.5 mmol) was dissolved in $10 \mathrm{~mL}$ methanol or ethanol in an oil-bath thermostated at $90^{\circ} \mathrm{C}$ until a homogeneous solution was obtained. TREN (1.965 g, $11.6 \mathrm{mmol}), m$-xylylene diamine (1.579 g, $11.6 \mathrm{mmol})$ and para-toluene sulfonic acid (25 mg, $0.13 \mathrm{mmol}$ ) were mixed in a vial and ultrasoned until the acid completely dissolved in the amines. To this mixture, $5 \mathrm{~mL}$ methanol was added, mixed until a homogeneous mixture was obtained and added to the acetoacetamide solution. After stirring, this solution was gently poured over the pre-heated glass fiber and manually spread using a pressure roller until all fibers were impregnated. The glass plate with the composite was put in a preheated oven at $60^{\circ} \mathrm{C}$ for 30 minutes after which the sample could be removed from the glass plate. The composite was further cured for 30 minutes at $90^{\circ} \mathrm{C}$ followed by $1 \mathrm{~h}$ at $170^{\circ} \mathrm{C}$ in vacuo yielding a completely cured single-layer stable prepreg.

\section{ASSOCIATED CONTENT}

\section{Supporting Information.}

This material is available free of charge via the Internet at http://pubs.acs.org.

Experimental details, material characterization and supplemental figures and tables.

\section{AUTHOR INFORMATION}

\section{Corresponding Author}

*E-mail: filip.duprez@ugent.be; johan.winne@ugent.be

\section{ACKNOWLEDGMENT}

Bernhard De Meyer and Bastiaan Dhanis are acknowledged for laboratory support. We are grateful to Renaud Nicolaÿ for discussions and feedback on the work.

W.D. thanks the Flanders innovation \& entrepreneurship (VlAIO) for a Ph.D. scholarship. F.D.P acknowledges UGent funding (BOF-GOA). 


\section{REFERENCES}

1. Capelot, M.; Montarnal, D.; Tournilhac, F.; Leibler, L., Metal-Catalyzed Transesterification for Healing and Assembling of Thermosets. Journal of the American Chemical Society 2012, 134 (18), 7664-7667.

2. $\quad$ Capelot, M.; Unterlass, M. M.; Tournilhac, F.; Leibler, L., Catalytic Control of the Vitrimer Glass Transition. ACS Macro Letters 2012, 1 (7), 789-792.

3. Montarnal, D.; Capelot, M.; Tournilhac, F.; Leibler, L., Silica-Like Malleable Materials from Permanent Organic Networks. Science 2011, 334 (6058), 965-968.

4. Angell, C. A., Formation of Glasses from Liquids and Biopolymers. Science 1995, 267 (5206), 1924-1935.

5. Bowman, C. N.; Kloxin, C. J., Covalent Adaptable Networks: Reversible Bond Structures Incorporated in Polymer Networks. Angewandte Chemie International Edition 2012, 51 (18), 4272-4274.

6. Kloxin, C. J.; Bowman, C. N., Covalent adaptable networks: smart, reconfigurable and responsive network systems. Chemical Society Reviews 2013, 42 (17), 7161-7173.

7. Kloxin, C. J.; Scott, T. F.; Adzima, B. J.; Bowman, C. N., Covalent Adaptable Networks (CANs): A Unique Paradigm in CrossLinked Polymers. Macromolecules 2010, 43 (6), 2643-2653.

8. Rekondo, A.; Martin, R.; Luzuriaga, A. R. d.; Cabañero, G.; Grande, H. J.; Odriozola, I., Catalyst-free room-temperature selfhealing elastomers based on aromatic disulfide metathesis. Mater. Horiz. 2013, 1, 237-240.

9. Obadia, M. M.; Mudraboyina, B. P.; Serghei, A.; Montarnal, D.; Drockenmuller, E., Reprocessing and Recycling of Highly Cross-Linked Ion-Conducting Networks through Transalkylation Exchanges of C-N Bonds. Journal of the American Chemical Society 2015,137 (18), 6078-6083.

10. Lu, Y.-X.; Guan, Z., Olefin Metathesis for Effective Polymer Healing via Dynamic Exchange of Strong Carbon-Carbon Double Bonds. Journal of the American Chemical Society 2012, 134 (34), 14226-14231.

11. Lu, Y.-X.; Tournilhac, F.; Leibler, L.; Guan, Z., Making Insoluble Polymer Networks Malleable via Olefin Metathesis. Journal of the American Chemical Society 2012, 134 (20), 8424-8427.

12. Denissen, W.; Rivero, G.; Nicolaÿ, R.; Leibler, L.; Winne, J. M.; Du Prez, F. E., Vinylogous urethane vitrimers. Advanced Functional materials 2015, 25 (16), 2451-2457.

13. Denissen, W.; Droesbeke, M.; Nicolaÿ, R.; Leibler, L.; Winne, J. M.; Du Prez, F. E., Chemical control of the viscoelastic properties of vinylogous urethane vitrimers. Nat. Comm. 2017, 8, 14857.

14. Zhang, H.; Wang, D.; Liu, W.; Li, P.; Liu, J.; Liu, C.; Zhang, J.; Zhao, N.; Xu, J., Recyclable polybutadiene elastomer based on dynamic imine bond. J. Polym. Sci. A Polym. Chem. 2017.

15. Taynton, P.; Ni, H.; Zhu, C.; Yu, K.; Loob, S.; Jin, Y.; Qi, H. J.; Zhang, W., Repairable Woven Carbon Fiber Composites with Full Recyclability Enabled by Malleable Polyimine Networks. Advanced Materials 2016, 28 (15), 2904-2909.

16. Taynton, P.; Yu, K.; Shoemaker, R. K.; Jin, Y.; Qi, H. J.; Zhang, W., Heat- or Water-Driven Malleability in a Highly Recyclable Covalent Network Polymer. Advanced Materials 2014, 26 (23), 3938-3942.

17. Cromwell, O. R.; Chung, J.; Guan, Z., Malleable and SelfHealing Covalent Polymer Networks through Tunable Dynamic
Boronic Ester Bonds. Journal of the American Chemical Society 2015, 137 (20), 6492-6495.

18. Hendriks, B.; Waelkens, J.; Winne, J. M.; Du Prez, F. E., Poly(thioether) Vitrimers via Transalkylation of Trialkylsulfonium Salts. ACS Macro Letters 2017, 6 (9), 930-934.

19. Röttger, M.; Domenech, T.; van der Weegen, R.; Breuillac, A.; Nicolaÿ, R.; Leibler, L., High-performance vitrimers from commodity thermoplastics through dioxaborolane metathesis. Science 2017, 356 (6333), 62-65.

20. Denissen, W.; Winne, J. M.; Du Prez, F. E., Vitrimers: permanent organic networks with glass-like fluidity. Chemical Science 2016, 7 (1), 30-38.

21. Zou, W.; Dong, J.; Luo, Y.; Zhao, Q.; Xie, T., Dynamic covalent polymer networks: From old chemistry to modern day innovations. Advanced Materials 2017, 29 (14).

22. García, F.; Smulders, M. M., Dynamic covalent polymers. J. Polym. Sci. A Polym. Chem. 2016, 54 (22), 3551-3577.

23. Demongeot, A.; Groote, R.; Goossens, H.; Hoeks, T.; Tournilhac, F.; Leibler, L., Cross-Linking of Poly(butylene terephthalate) by Reactive Extrusion Using Zn(II) Epoxy-Vitrimer Chemistry. Macromolecules 2017, 50 (16), 6117-6127.

24. Zhou, Y.; Goossens, J. G. P.; Sijbesma, R. P.; Heuts, J. P. A., Poly(butylene terephthalate)/Glycerol-based Vitrimers via SolidState Polymerization. Macromolecules 2017, 50 (17), 6742-6751.

25. Chabert, E.; Vial, J.; Cauchois, J.-P.; Mihaluta, M.; Tournilhac, F., Multiple welding of long fiber epoxy vitrimer composites. Soft Matter 2016, 12 (21), 4838-4845.

26. Odriozola, I.; Ruiz de Luzuriaga, A.; Rekondo, A.; Martin, R.; Markaide, N.; Cabañero, G.; Grande, H. J. Thermomechanically reprocessable epoxy composites and their manufacturing. EP2949679 A1, 2015.

27. Ruiz de Luzuriaga, A.; Martin, R.; Markaide, N.; Rekondo, A.; Cabanero, G.; Rodriguez, J.; Odriozola, I., Epoxy resin with exchangeable disulfide crosslinks to obtain reprocessable, repairable and recyclable fiber-reinforced thermoset composites. Mater. Horiz. 2016, 3 (3), 241-247.

28. de Almeida, S. F. M.; Neto, Z. d. S. N., Effect of void content on the strength of composite laminates. Composite Structures 1994, 28 (2), 139-148.

29. De Baere, I. Studie van afschuivingsgedrag van composieten. Universiteit Gent, 2004.

30. Sridharan, V.; Ruiz, M.; Carlos Menendez, J., Mild and High-Yielding Synthesis of beta-Keto Esters and beta-Ketoamides. Synthesis 2010, (6), 1053-1057.

31. Rout, L.; Kumar, A.; Dhaka, R. S.; Dash, P., Bimetallic Ag$\mathrm{Cu}$ alloy nanoparticles as a highly active catalyst for the enamination of 1,3-dicarbonyl compounds. RSC Adv. 2016, 6 (55), 4992349940.

32. Trumbo, D. L., Michael addition polymers from bisacetoacetates. Polymer Bulletin 1991, 26 (5), 481-485. 


\section{Synopsis}

Novel vitrimers based on the dynamic amine exchange of vinylogous are prepared from readily accessible chemicals. The fast kinetics of vinylogous urea embedded in a rigid vinylogous urea matrix yielded vitrimers with relaxation times in the order of seconds and proved to be useful as a matrix in composite materials.

vitrimers, dynamic chemistry, covalent adaptable networks, vinylogous acyls, vinylogous urea

\section{Graphical Abstract}

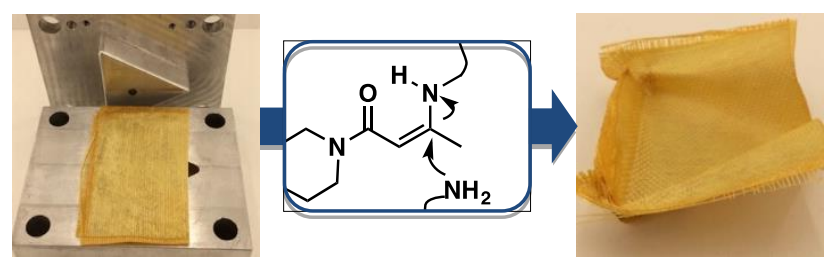

\section{$\underline{\text { Title }}$}

Vinylogous urea vitrimers and their application in fiber reinforced composites

\section{List of authours:}

Wim Denissen" ${ }^{1}$, Ives De Baere ${ }^{2}$, Wim Van Paepegem², Ludwik Leibler ${ }^{3}$, Johan Winne*1, Filip E. Du Prez ${ }^{* 1}$ 